\title{
Rashba Splitting in Two Dimensional Hybrid Perovskite Materials for High Efficient Solar and Heat Energy Harvesting
}

\author{
Hardik L. Kagdada ${ }^{1}$, Sanjeev K Gupta ${ }^{2}$, Satyaprakash Sahoo ${ }^{3,4}$, Dheeraj K. Singh ${ }^{1, *}$ \\ ${ }^{1}$ Department of Physics, Institute of Infrastructure Technology Research And Management (IITRAM), \\ Ahmedabad 380026, India \\ ${ }^{2}$ Computational Materials and Nanoscience Group, Department of Physics, St. Xavier's College, \\ Ahmedabad 380009, India \\ ${ }^{3}$ Institute of Physics, Bhubaneswar 751005, India \\ ${ }^{4}$ Homi Bhabha National Institute, Anushaktinagar, Mumbai 400 085, India \\ *Corresponding author: dheerajsingh84@gmail.com; dheerajsingh@iitram.ac.in
}




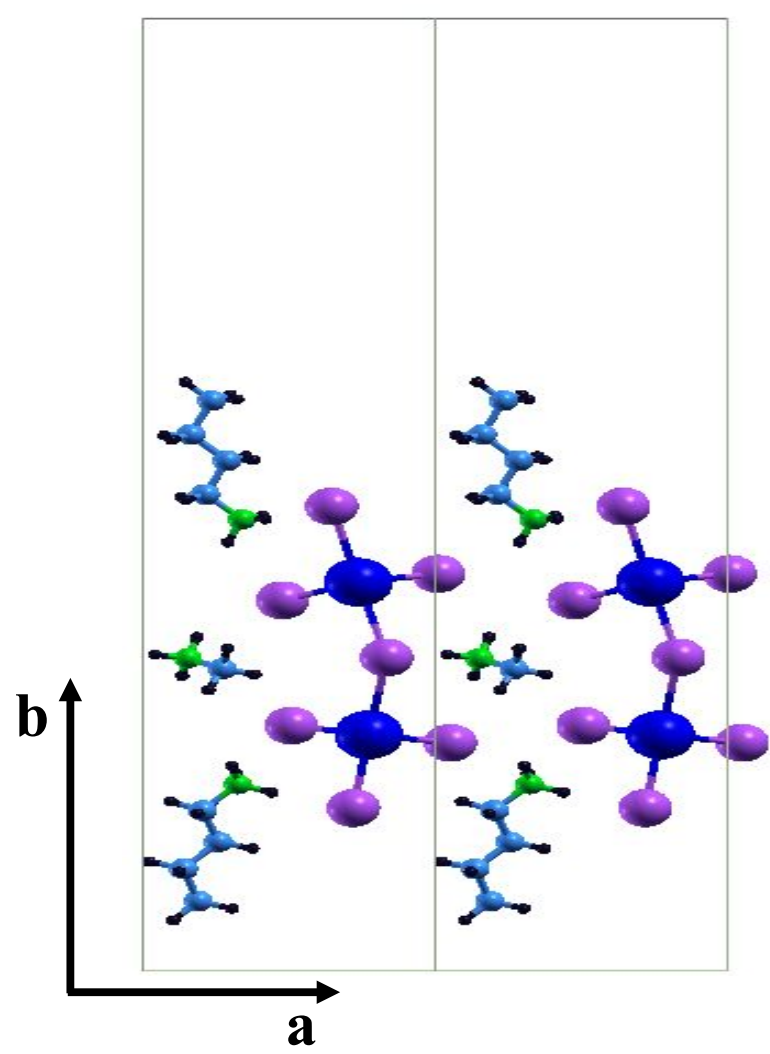

M1

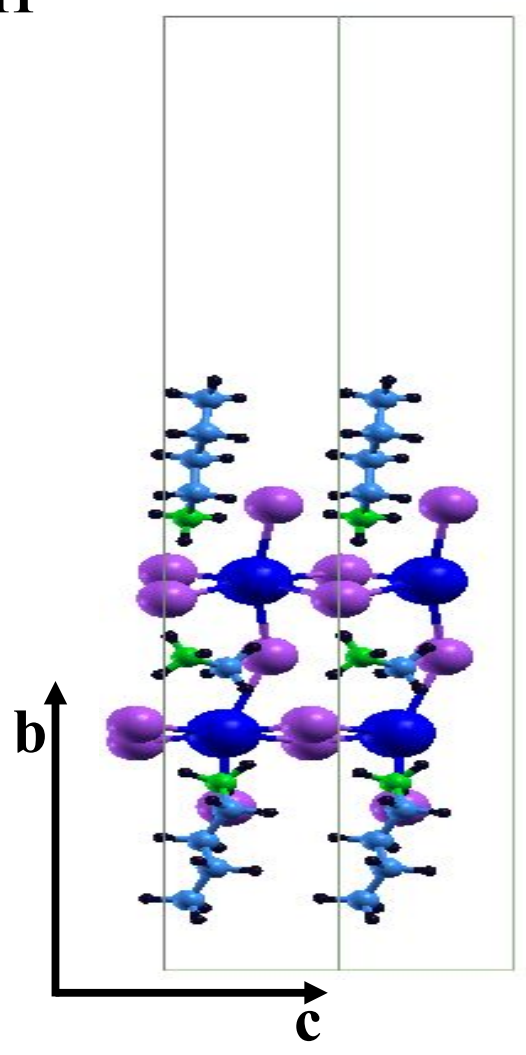

M2
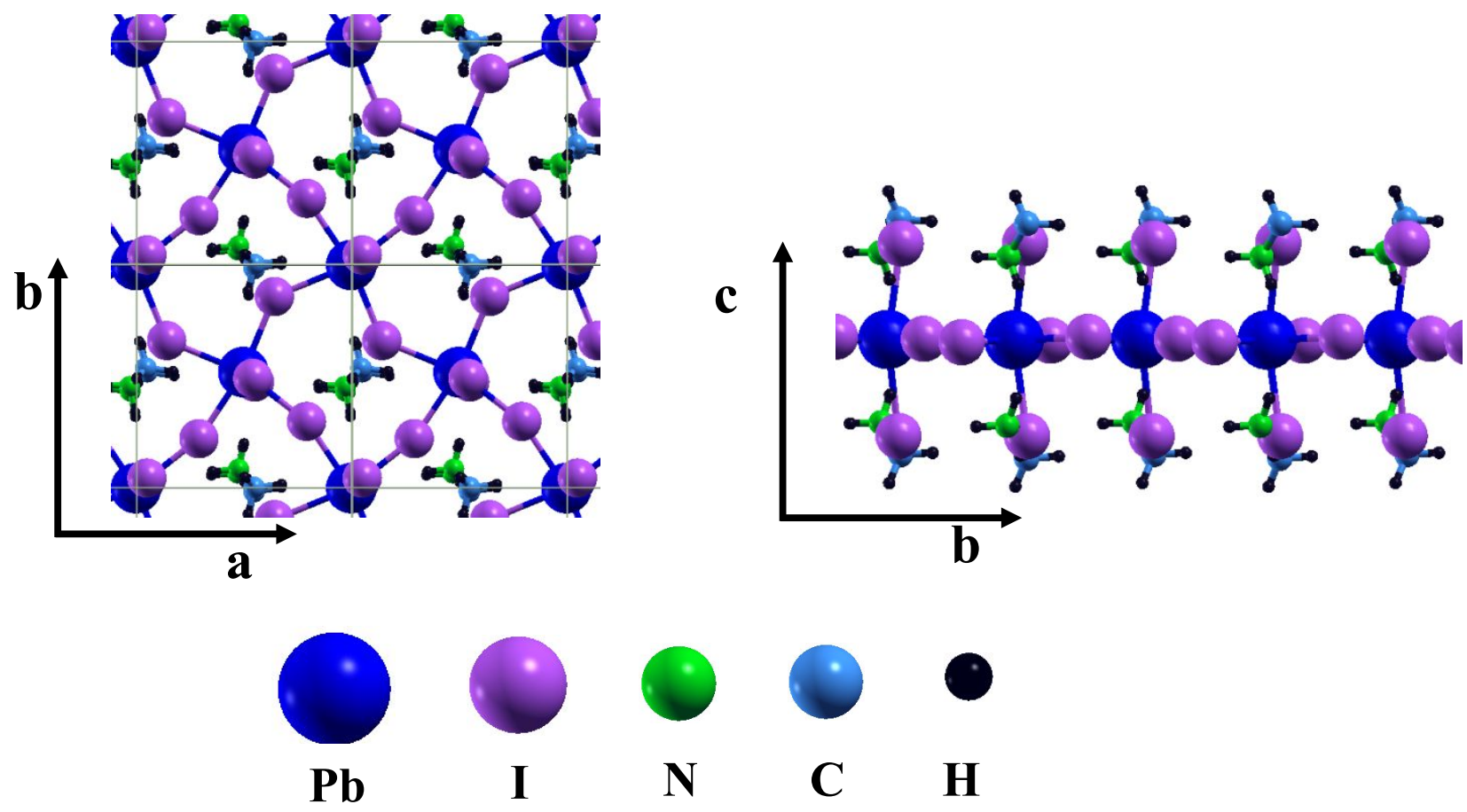

Figure S1. 2D structures of consider perovskite material. Here, $2 \times 2$ supercell of unit cell structure is presented. Two orthorhombic structures are predicted for the present study, names as M1 (upper panel) and M2 (lower panel). Black, green, skyblue, pink and dark blue color spheres represents the $\mathrm{H}, \mathrm{N}, \mathrm{C}, \mathrm{I}$ and $\mathrm{Pb}$ atoms, respectively. 
Table S1: Atomic position for M1 structure in crystal units. The lattice parameters are a $=8.474$ $\AA, b=39.347 \AA, c=4.518 \AA, \alpha=90^{\circ}, \beta=90^{\circ}$, and $\gamma=90^{\circ}$.

\begin{tabular}{|c|c|c|c|}
\hline Atom & $\mathbf{x}$ & $\mathbf{y}$ & $\mathbf{z}$ \\
\hline $\mathrm{Pb}$ & 0.77252 & 0.24788 & 0.33392 \\
\hline $\mathrm{Pb}$ & 0.73719 & 0.40809 & 0.51753 \\
\hline I & 1.05228 & 0.23939 & -0.16126 \\
\hline I & 0.50682 & 0.25744 & -0.16636 \\
\hline I & 0.47642 & 0.38916 & 0.01133 \\
\hline I & 1.01033 & 0.41691 & 0.01551 \\
\hline I & 0.83353 & 0.32902 & 0.59836 \\
\hline I & 0.64524 & 0.48753 & 0.62738 \\
\hline $\mathrm{I}$ & 0.71971 & 0.17092 & 0.35305 \\
\hline $\mathrm{N}$ & 0.15135 & 0.32812 & 0.12881 \\
\hline $\mathrm{H}$ & 0.04136 & 0.33219 & 0.23095 \\
\hline $\mathrm{H}$ & 0.13287 & 0.30969 & -0.02973 \\
\hline $\mathrm{H}$ & 0.18408 & 0.35059 & 0.02791 \\
\hline $\mathrm{C}$ & 0.26917 & 0.31723 & 0.35396 \\
\hline $\mathrm{H}$ & 0.3806 & 0.31125 & 0.24442 \\
\hline $\mathrm{H}$ & 0.22298 & 0.2947 & 0.46688 \\
\hline $\mathrm{H}$ & 0.28805 & 0.33823 & 0.50865 \\
\hline $\mathrm{N}$ & 0.33734 & 0.47389 & 0.13314 \\
\hline $\mathrm{H}$ & 0.28914 & 0.44983 & 0.11367 \\
\hline $\mathrm{H}$ & 0.41685 & 0.4743 & 0.31123 \\
\hline $\mathrm{H}$ & 0.40991 & 0.47814 & -0.05104 \\
\hline $\mathrm{C}$ & 0.21285 & 0.5004 & 0.16686 \\
\hline $\mathrm{H}$ & 0.14683 & 0.49447 & 0.3695 \\
\hline $\mathrm{H}$ & 0.13021 & 0.49752 & -0.01846 \\
\hline $\mathrm{C}$ & 0.2861 & 0.53567 & 0.17832 \\
\hline $\mathrm{H}$ & 0.37509 & 0.5365 & 0.35596 \\
\hline $\mathrm{H}$ & 0.35011 & 0.54052 & -0.02967 \\
\hline $\mathrm{C}$ & 0.16136 & 0.56312 & 0.22904 \\
\hline $\mathrm{H}$ & 0.07315 & 0.56216 & 0.05028 \\
\hline $\mathrm{H}$ & 0.09702 & 0.55755 & 0.43518 \\
\hline $\mathrm{C}$ & 0.23425 & 0.5986 & 0.24678 \\
\hline
\end{tabular}




\begin{tabular}{cccc}
$\mathrm{H}$ & 0.14406 & 0.61813 & 0.28482 \\
$\mathrm{H}$ & 0.29668 & 0.60493 & 0.04083 \\
$\mathrm{H}$ & 0.32024 & 0.60001 & 0.4285 \\
$\mathrm{~N}$ & 0.32308 & 0.19597 & 0.32539 \\
$\mathrm{H}$ & 0.30463 & 0.21549 & 0.47443 \\
$\mathrm{H}$ & 0.31814 & 0.20691 & 0.11783 \\
$\mathrm{H}$ & 0.43944 & 0.18719 & 0.35524 \\
$\mathrm{C}$ & 0.20298 & 0.16842 & 0.36278 \\
$\mathrm{H}$ & 0.09125 & 0.17781 & 0.27111 \\
$\mathrm{H}$ & 0.18535 & 0.16512 & 0.60117 \\
$\mathrm{C}$ & 0.25678 & 0.13553 & 0.21881 \\
$\mathrm{H}$ & 0.37332 & 0.12841 & 0.30735 \\
$\mathrm{H}$ & 0.27287 & 0.1393 & -0.02087 \\
$\mathrm{C}$ & 0.13718 & 0.10714 & 0.27553 \\
$\mathrm{H}$ & 0.12286 & 0.10418 & 0.51638 \\
$\mathrm{H}$ & 0.02076 & 0.11483 & 0.19085 \\
$\mathrm{C}$ & 0.1876 & 0.07334 & 0.13861 \\
$\mathrm{H}$ & 0.1028 & 0.05316 & 0.19118 \\
$\mathrm{H}$ & 0.30377 & 0.06533 & 0.22098 \\
$\mathrm{H}$ & 0.19571 & 0.07529 & -0.10351 \\
\hline
\end{tabular}


Table S2: Atomic position for M2 structure in crystal units. The lattice parameters are a $=8.548$ $\AA, b=8.870 \AA, c=20 \AA, \alpha=90^{\circ}, \beta=90^{\circ}$, and $\gamma=90^{\circ}$.

\begin{tabular}{|c|c|c|c|}
\hline Atom & $\mathbf{x}$ & $\mathbf{y}$ & $\mathbf{z}$ \\
\hline $\mathrm{Pb}$ & 0.495228 & 0.538316 & 0.741097 \\
\hline $\mathrm{Pb}$ & 0.996316 & 1.036081 & 0.742958 \\
\hline I & 0.53887 & 0.509239 & 1.124104 \\
\hline I & 0.138933 & 0.684804 & 0.745464 \\
\hline I & 0.047307 & 0.045587 & 1.122721 \\
\hline I & 0.28859 & 0.228667 & 0.732241 \\
\hline I & 0.639393 & 0.889271 & 0.738287 \\
\hline I & 0.788464 & 0.308682 & 0.75325 \\
\hline I & 0.546822 & 0.492149 & 0.360842 \\
\hline I & 0.038566 & 0.029545 & 0.361377 \\
\hline $\mathrm{C}$ & 0.041614 & 0.55685 & 1.218687 \\
\hline $\mathrm{C}$ & 0.047301 & 0.539868 & 0.28748 \\
\hline $\mathrm{C}$ & 0.545226 & 1.020255 & 0.272561 \\
\hline $\mathrm{C}$ & 0.545592 & 1.039474 & 1.20151 \\
\hline $\mathrm{N}$ & 0.966078 & 0.470882 & 1.086769 \\
\hline $\mathrm{N}$ & 0.472686 & 0.087061 & 1.068423 \\
\hline $\mathrm{N}$ & 0.467653 & 0.069214 & 0.40216 \\
\hline $\mathrm{N}$ & 0.969069 & 0.450049 & 0.414919 \\
\hline $\mathrm{H}$ & 0.847562 & 0.46227 & 0.410261 \\
\hline $\mathrm{H}$ & 0.99319 & 0.330564 & 0.407781 \\
\hline $\mathrm{H}$ & 0.500924 & 1.0646 & 0.161176 \\
\hline $\mathrm{H}$ & 1.005379 & 0.488822 & 0.523952 \\
\hline $\mathrm{H}$ & 0.671719 & 1.038565 & 0.280909 \\
\hline $\mathrm{H}$ & 1.021316 & 0.663895 & 0.302178 \\
\hline $\mathrm{H}$ & 0.519066 & 0.895507 & 0.284012 \\
\hline $\mathrm{H}$ & 0.50345 & 1.065055 & 0.510197 \\
\hline $\mathrm{H}$ & 0.492739 & 0.188678 & 0.398555 \\
\hline $\mathrm{H}$ & 0.346126 & 0.058123 & 0.398098 \\
\hline $\mathrm{H}$ & 0.173698 & 0.520404 & 0.294697 \\
\hline $\mathrm{H}$ & 0.002278 & 0.498531 & 0.175256 \\
\hline $\mathrm{H}$ & 0.498236 & 0.206361 & 1.071995 \\
\hline
\end{tabular}




\begin{tabular}{cccc}
$\mathrm{H}$ & 0.511005 & 0.043587 & 0.961724 \\
$\mathrm{H}$ & 0.168566 & 0.542434 & 1.210106 \\
$\mathrm{H}$ & -0.00118 & 0.5089 & 1.32923 \\
$\mathrm{H}$ & 0.515895 & 0.915337 & 1.192286 \\
$\mathrm{H}$ & 0.672582 & 1.054962 & 1.19605 \\
$\mathrm{H}$ & 0.500159 & 1.087836 & 1.310763 \\
$\mathrm{H}$ & 1.011763 & 0.680544 & 1.209908 \\
$\mathrm{H}$ & 0.844325 & 0.481041 & 1.089666 \\
$\mathrm{H}$ & 0.991873 & 0.351621 & 1.089119 \\
$\mathrm{H}$ & 1.003687 & 0.514358 & 0.979725 \\
$\mathrm{H}$ & 0.350428 & 1.11439 & 1.070609 \\
\hline
\end{tabular}
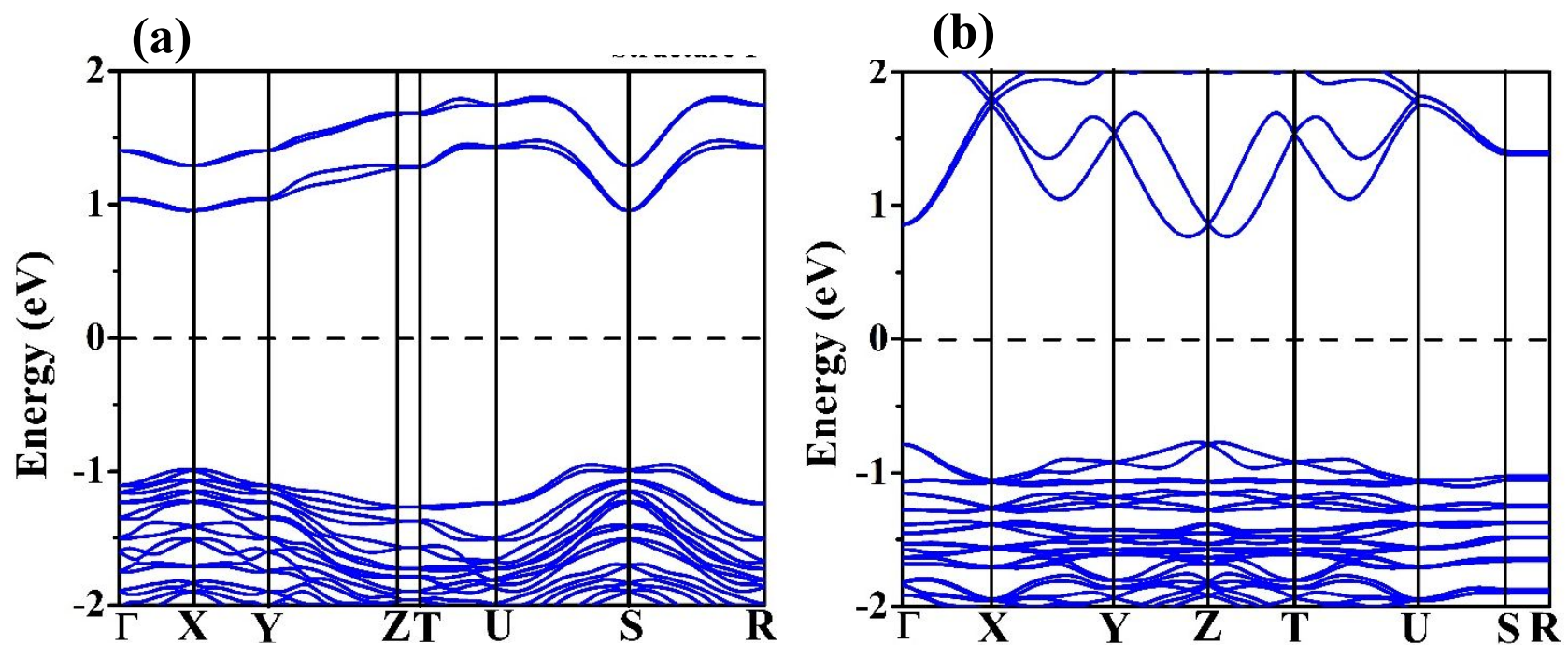

Figure S2. Full BZ SOC band structure for both the structure. Rashba splitting is clearly visible at the band edge of M2. 
(a)

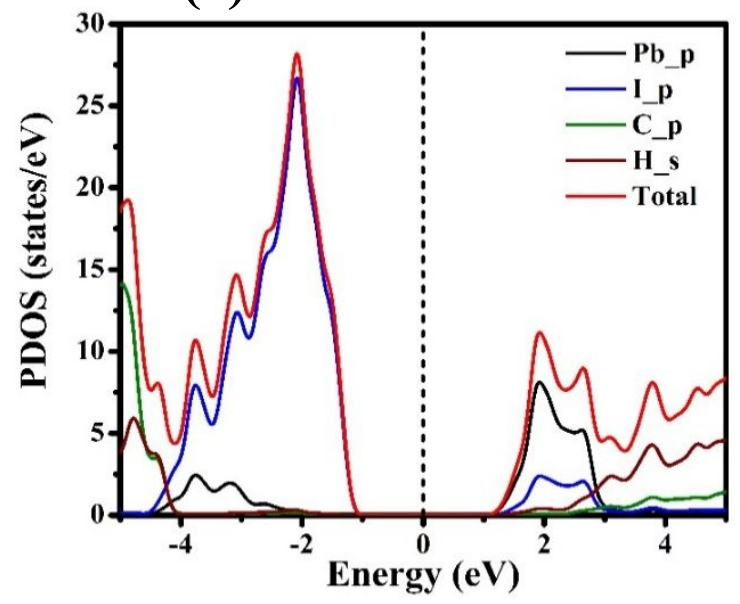

(b)

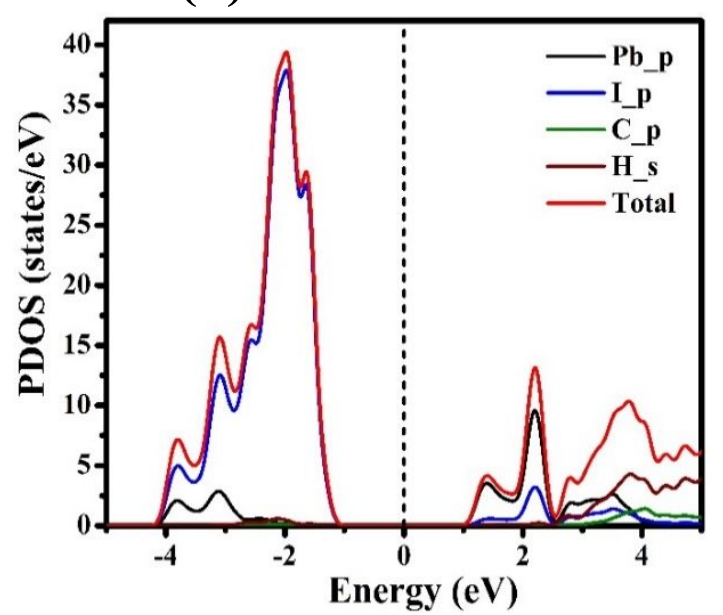

Figure S3. Projected density of states (PDOS) along with total DOS for (a) M1 and (b) M2. Here, both the structures follow basic condition for solar energy conversion i.e. the p-p transition.

\section{Projected density of states}

The contribution from each orbitals of electron is analyzed through the projected density of states (PDOS) without SOC and shown in Figure S3. It seems that valence band maximum (VBM) for the both structure formed through I $5 p$ orbitals majorly, while $\mathrm{Pb} 6 p$ and other orbitals contribute in the conduction band minimum. The effective optical absorber for solar energy conversion must acquire $p-p$ transition between VBM and CBM. From PDOS, one can observe that both the VBM and $\mathrm{CBM}$ are constructed from majority of I $5 p$ orbitals and $\mathrm{Pb} 6 p$ orbitals respectively, which suggests the $p-p$ transition in considered 2D hybrid perovskite leads to the strong candidate for efficient optical absorption. Additionally, near the Fermi level the contribution of $\mathrm{Pb}$ and I atoms on CBM and VBM is quite higher in case of M2 structure, which might have significant effect on the transport properties. Moreover, a deeper analysis of PDOS near Fermi energy suggests that the extra BA organic cations interact with the $\mathrm{PbI}_{6}$ octahedral through the vdW force results in the more tilting of inorganic part in M1 than M2. Further, the contribution of organic cation is 
negligible near to the Fermi level, which reveals that the interaction with inorganic $\mathrm{PbI}_{6}$ is electrostatic and giving the advantage of charge neutralization with inorganic cation.
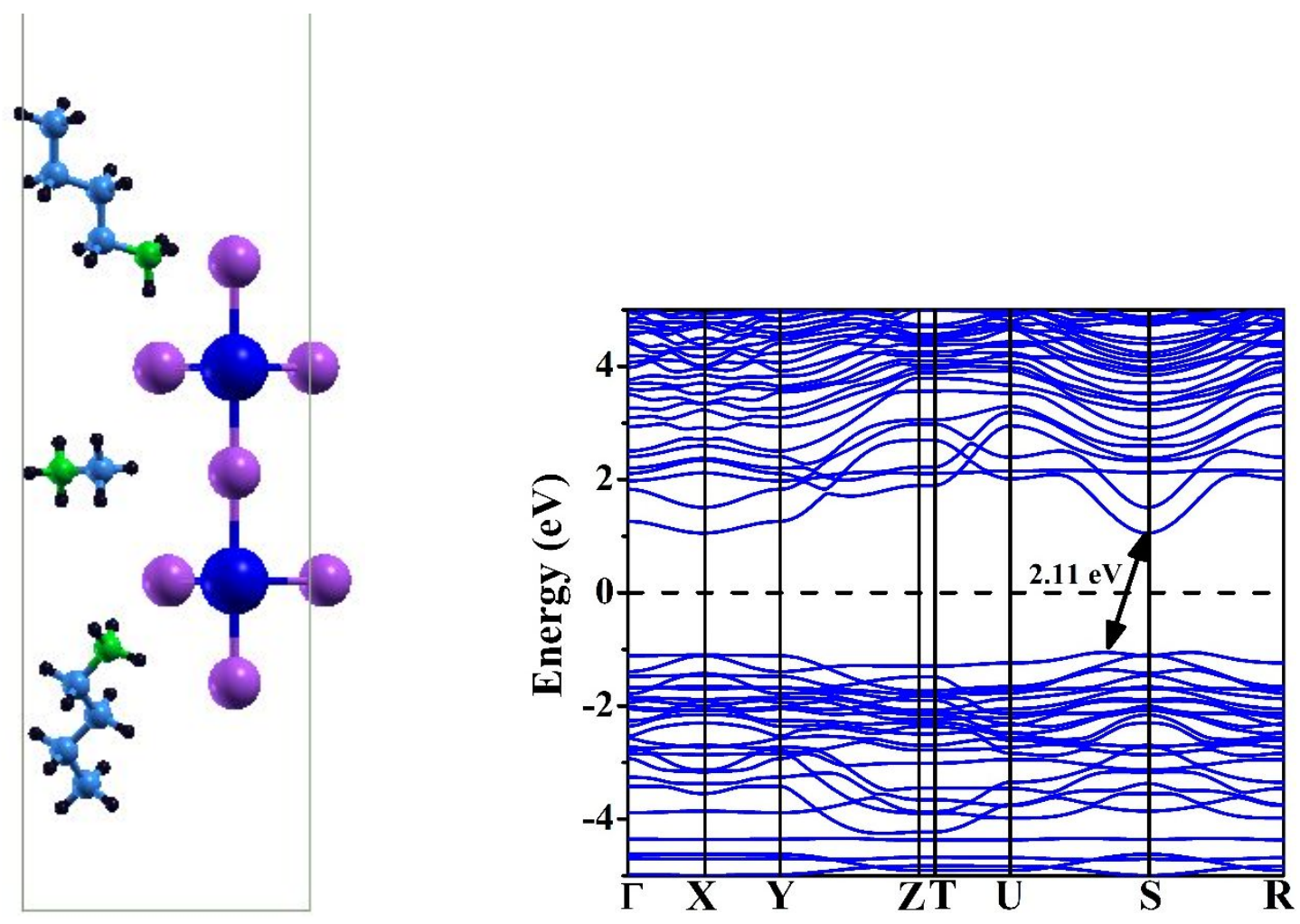

Figure S4. (a) Unit cell of M1 structure with centrosymmetric configuration of Pb-I framework. (b) Electronic band structure without SOC for the centrosymmetric M1. Color code of atoms in (a) is same as presented in Fig. S1. 

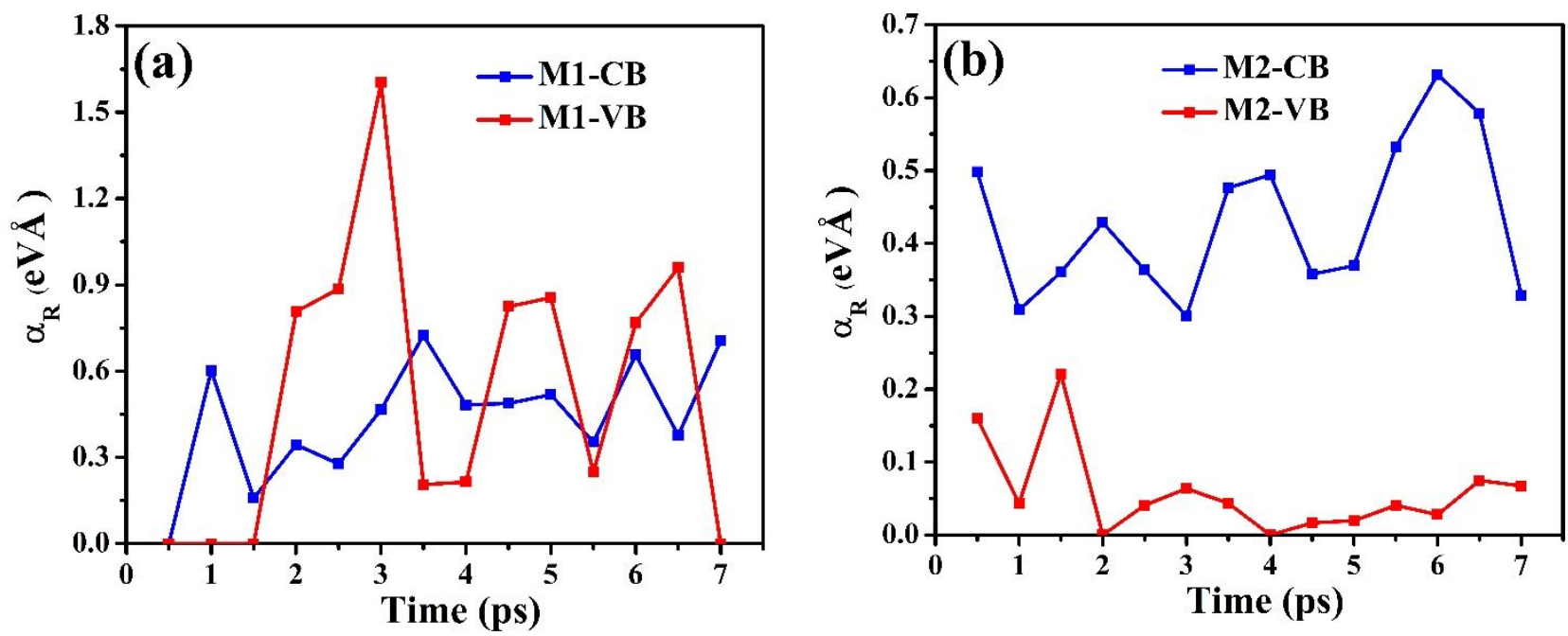

Figure S5. Dynamical Rashba coefficient $\left(\alpha_{R}\right)$ at picosecond (ps) time scale for (a) M1 and (b) M2 structure.

(a)

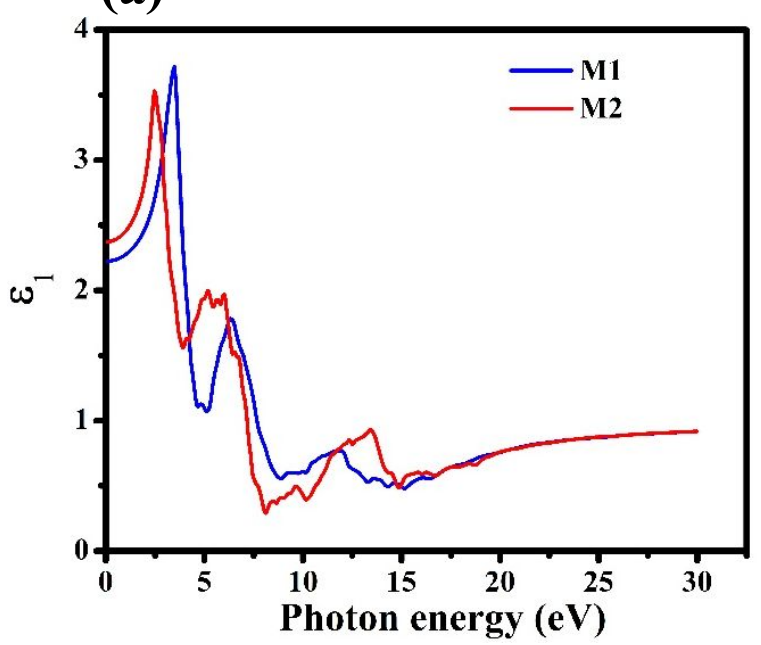

(b)

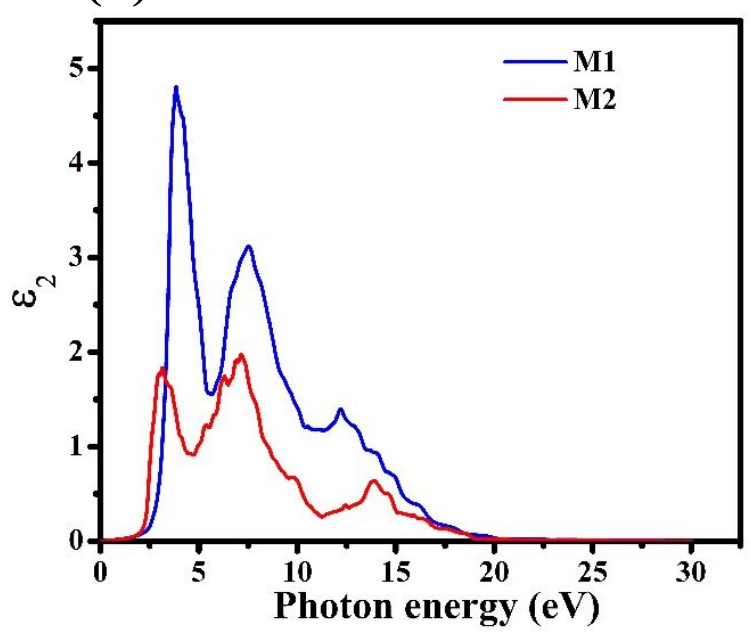

Figure S6. (a) Real $\left(\varepsilon_{1}\right)$, (b) imaginary $\left(\varepsilon_{2}\right)$ part of dielectric function $(\varepsilon)$ for both structures. 